\title{
Oral Rehydration Therapy Utilization and Associated Factors Among Children with Diarrhea in Debre Berhan, Ethiopia, 2020
}

\author{
Abate Dargie Wubetu (D) \\ Abayneh Shewangzaw Engda' \\ Hailu Belay Yigzaw ${ }^{2}$ \\ Getaneh Baye Mulu (D) $^{3}$ \\ 'Debre Berhan University, College of \\ Health Science, Department of \\ Psychiatry, Debre Berhan, Amhara, \\ Ethiopia; ${ }^{2}$ Adigrat University, College of \\ Health Science, Department of \\ Psychiatry, Adigrat, Tigray, Ethiopa; \\ ${ }^{3}$ Debre Berhan University, College of \\ Health Science, Department of Nursing, \\ Debre Berhan, Amhara, Ethiopia
}

Background: Oral rehydration therapy is a critical intervention to save the lives of children during episodes of diarrhea and vomiting. However, millions of children die every year due to failure to replace fluid effectively. Nearly all dehydration-related deaths can be preventable by prompt administration of rehydration therapy. The current study aimed to assess oral rehydration therapy utilization and associated factors among children with diarrhea in Debre Berhan town.

Methods: Community-based cross-sectional study was conducted from February to March 2020. The study participants were selected by systematic random sampling. The first household was selected randomly by the lottery method. The collected data were checked for completeness and relevance, and then entered into EPI data and transferred to SPSS for analysis. Multivariate logistic regression was used to determine the ORT utilization and predictor variables. A p-value less than 0.05 was considered a cutoff point for statistical significance for all statistical tests.

Results: The study included 233 participants with a 99\% response rate. Among them, $73 \%$ [95\% Cl: 66.878 .6$]$ of caregivers had given oral rehydration therapy to their children. Previous use of oral rehydration therapy [AOR: 5.3, Cl: 2.1-13.32], healthseeking behavior [AOR: 5.7, $\mathrm{Cl}$ : 2.07-15.6], knowledge about oral rehydration therapy [AOR: 4.2, Cl: 1.7-10.46], caregivers' perception of tooth eruption [AOR: 3.13, Cl: 1.08-9], weaning as causes of diarrhea [AOR: 6.7, $\mathrm{Cl}: 2.49-17.9$ ], and recognize the severity sign of dehydration [AOR: $5.6, \mathrm{Cl}: 2.16-14.7$ ] became significant factors of oral rehydration therapy.

Conclusion: Nearly two-thirds of the mothers give oral rehydration therapy while their child develops diarrhea. Mothers had previous oral rehydration therapy, good health-seeking behavior, knowledge about oral rehydration therapy, caregivers' perception of tooth eruption, and weaning as causes of diarrhea. Signs to recognize the severity of dehydration were important factors with oral rehydration therapy utilization. It will be better to give mothers special attention to hindering factors from giving oral rehydration therapy for their beloved child during diarrheal disease.

Keywords: ORT, children, associated factors, Amhara, North Shoa, Ethiopia

\section{Background}

World Health Organization (WHO) defines diarrhea as the passage of three or more loose or liquid stools per day (or more frequent passage of diarrhea than normal for the individual). Frequent passing of formed stools is not diarrhea, nor is the passing of loose, "pasty" stools by breastfed babies. In children aged less than five years,
Correspondence: Abate Dargie Wubetu Email abatedargie200I@gmial.com 
diarrheal diseases account for 1.7 billion cases and 525,000 deaths yearly and remain the second leading cause of death. ${ }^{1,2}$

It results in loss of body fluid and electrolyte, leading to severe dehydration, electrolyte imbalance, shock, and even death. ${ }^{3}$ Since the immediate cause of death in most cases is dehydration, these deaths are almost entirely preventable if dehydration prevented or treated promptly. Children of developing countries are highly affected by diarrheal disease. In Africa, every child experienced five episodes of diarrhea yearly, and about 800,000 children die due to diarrheal dehydration annually. From these, $42 \%$ of deaths accumulated in Sub-Saharan African countries. ${ }^{1,4}$

These children die due to inadequate use of ORT by caregivers, and these deaths are mainly because of dehydration that ORT can quickly treat. Ethiopia stands fifth globally, accounting for $20-27 \%$ of child death caused by diarrhea and its complications. ${ }^{5,6}$ ORT established as the cornerstone of dehydration secondary to diarrhea forty years ago, which is simple, inexpensive, and the most effective way to treat dehydration. It can be easily administered at home by the mothers /caregivers as soon as the diarrhea episode begins. The universal use of ORT for diarrhea could prevent almost 1.5 million deaths per year or $15 \%$ of all under-five deaths. ${ }^{7-9}$

WHO and Integrated Management of Neonatal and Childhood Illness (IMNCI) diarrheal management guidelines encourage mothers and caretakers to treat diarrhea at home by giving ORS and ORT to reduce the duration, severity, hospitalization, overall medical costs, and death. ${ }^{10}$ Even if global ORS access rates have improved substantially over the past four decades, rates of ORS use have stagnated, demanding an investigation to understand which interventions effectively promote ORS use and where there are gaps in the literature. ${ }^{11}$

Despite remarkable progress in reducing under-five mortality in Ethiopia, under-five diarrhea is still the leading cause of mortality and morbidity; it is the primary killer of children. ${ }^{12}$ According to EDHS 2016, diarrheal disease affects about $12 \%$ of under-five children. Among them, less than half of children with diarrheal disorder sought treatment. Among those who sought treatment, three in ten children received a rehydration solution from an oral rehydration salt (ORS) packet. In the Amhara region, the prevalence of rehydration therapy was $28 \% .{ }^{13}$ Another study in Arba Minch indicated that diarrhea is the second cause for clinical presentation among under five-year child population next to pneumonia. ${ }^{6}$
Several associated factors for ORT utilization identified across the world. The potential risk factors include, but not limited to, age of caregiver, educational level, and income, number of under-five children, access to ORT, caregivers' knowledge about ORT, previous use of ORT, advice or treatment from health facilities, and availability of ORS sachet at home. However, risk factors are not always global. Risk assessment should be carried out progressively at local, regional, and international levels. ${ }^{14-19}$

Evidence showed that in several countries, rehydration fluids' behavior to children with diarrhea had improving fashion. Activities to strengthen diarrhea management and reduce childhood deaths from diarrhea must be scaled up. Furthermore, the magnitude and the gap of oral rehydration therapy utilization were not assessed and known in the current study area. Therefore, this study intended to determine the extent and identify associated factors of ORT utilization.

\section{Methods}

\section{Study Area and Period}

The study was conducted in Debre Berhan town, North Shoa Zone, the Amhara regional state, Ethiopia, from February to March 2020. The city is located $695 \mathrm{~km}$ from Bahir Dar and $130 \mathrm{~km}$ from Addis Ababa. The under-five total population during 2019 was 15,528. Four hundred eighty-seven children suffered from diarrheal disease. The health system is represented by one public comprehensive and referral hospital, one private general hospital, and three health centers. In addition to this, there are five medium clinics owned by the private sector.

\section{Study Design}

A community-based cross-sectional study design was employed.

\section{Population}

All households with under-five children with diarrhea disease in Debre Berhan town were considered the source population of the study. All families with under-five children with diarrhea and available during the study period in Debre Berhan town are the study population. The selected households with under-five children with diarrhea during the study period were also considered the sampling unit. Mothers-child pairs that gave the actual data during the data collection period were the study unit. 


\section{Sample Size Determination}

The sample size was determined by using a single population proportion formula as follows: A proportion of $58.2 \%$ from a similar study done in Ethiopia, Asela, ${ }^{7}$ and $5 \%$ of margin of error were considered. The sample size was 374 households who had children with diarrheal disease. The sample size was reduced by using the sample size correction formula, and finally, it became 213 households. After a $10 \%$ non-response rate added, the final sample size became 235 households who had children with diarrheal disease.

\section{Sampling Technique and Procedure}

The town has nine sub-administrations (locally known as Kebele), and all of the Kebeles were included in the study. We used the health extension workers to get the household list with under-five children. We did a screening survey to identify households with children having diarrheal disease currently and previously. Then the sample was proportionally allocated to each Kebele. Finally, a simple random sampling technique was employed to select the study subjects - the household random numbers generated by using Open Epi software.

\section{Study Variables \\ Dependent Variable}

Oral rehydration therapy utilization.

\section{Independent Variable}

Socio-Demographic Characteristics

Age of child, number of $<5$ years children, parental education, occupation, family size, age of caregivers, the gender of caregivers, monthly income, access to ORT, and marital status were included.

\section{Caregivers' Behavior}

Knowledge about ORT, previous use of ORT, advice or treatment from health facilities, and availability of ORS sachet at home were included.

\section{Caregivers Perceived Causes and Morbidity of Diarrhea} Caregivers' perception of the causes of diarrhea, number of signs identified to recognize the severity of diarrhea, and dehydration will be included.

\section{Operational Definition Dehydration}

Children with diarrhea having dry mouth or skin, sunken eyes, eagerness/unable to drink, slight/no urination, sleepiness, or lethargy.

\section{Oral Rehydration Therapy (ORT)}

Administrate recommended fluid or ORS by mouth to prevent or correct dehydration due to diarrhea.

\section{Oral Rehydration Salt (ORS)}

A solution used to replace water and electrolyte secondary to diarrhea.

\section{Primary Caregiver}

An individual who is spending many hours taking care of a child.

\section{Diarrhea}

The passage of $\geq 3$ loose stools per day or watery stool of any frequent.

\section{Data Collection Tools}

First, the English version of the questionnaire was prepared. The questionnaire was translated back to check its sharpness to assess the intended outcome. Data were collected using structured interviewer-administered questionnaires from primary caregivers of under-five children. The questionnaires included data on primary caregiver and child socio-demographic characteristics, caregiver behavior, and perception. For socio-demographic factors, questionnaire constructs were developed from the previous related articles. A pre-tested questionnaire assessed the primary caregivers' knowledge, behavior, and perceived cause of diarrhea. The dependent variable (ORT) screened using the World Health Organization's diarrheal treatment utilization recommendation. ${ }^{2}$ The questionnaire's internal consistency managed by using Cronbach's alpha. The Cronbach alpha results were tolerable to use the assessment tools. It ranges from $0.75,0.82$ and 0.86 for knowledge, behavior, and perceived cause variables.

\section{Data Quality Control}

Experts in related fields evaluated the questionnaire. Three health extension workers were selected as data collectors, and one health officer was also chosen for supervision. The data collection instrument was pre-tested on $5 \%$ of the sample size in a different health center to avoid information contamination. The pre-test was used to check for language clarity, appropriateness of data collection tools, estimate the time required, and consider the necessary amendments. The training was given for both data collectors and supervisors concerning the data abstraction tool and data collection process. During the data collection 
time, close supervision was carried out by the supervisor to ensure the quality of the data. Finally, the supervisor and investigators checked all the collected data for its completeness and consistency. Consistency was examined through a random selection of questionnaires.

\section{Data Processing and Analysis}

The collected data were cleaned, edited, and coded before analysis. Any errors identified were corrected after reviewing the original data using the code numbers. Data were entered using Epi-Data version 4.2.1 and analyzed using SPSS 25 statistical software. Based on the nature of variables, frequency distribution, summary statistics such as mean and standard deviation was computed. The bivariate logistic regression analysis was held to identify an explanatory variable that is eligible for multivariate regression. Those variables having a p-value less than or equals to 0.25 during bivariate analysis were exported to the multivariable logistic regression model. In multivariable regression, a p-value less than 0.05 was considered statistically significant.

\section{Results}

\section{Prevalence of Oral Rehydration Therapy Utilization}

The study included 233 under-five children and their mothers/caregivers with a $98.3 \%$ response rate. Among the total primary caregivers, $73 \%$ [95\% Cl: 66.878 .6$]$ of caregivers had given oral rehydration therapy to their children.

\section{Socio-Demographic Information}

Concerning the age of the children, the majority of children were between 12 and 23 months of age with the mean age of $22.81 \pm 12.38(\mathrm{SD})$ months. The majority of mothers/caregivers, $148(63.5 \%)$, were in the age group of 25-35 years with a mean age of $30.81 \pm 6.88$ (SD) years. The majority (39.9\%) of mothers/caregivers were attended primary education, followed by secondary (29.2\%), and college and above (20.6\%). The minimum $(10.3 \%)$ of mothers/caregivers had no formal education. Two hundred three $(87.1 \%)$ were married, and 111 (47.6\%) were housewives. $71.7 \%$ and $60.9 \%$ of mothers/ caregivers were Amhara ethnic and Orthodox Christian followers. In terms of child-caregiver relation, most caregivers, 185 (79.4\%), were mothers. Regarding the family size, most participants had five or fewer family members, and $170(73 \%)$ of the family had their first child [Table 1].

\section{Primary Caregivers Behaviors Related Factors}

Variables like access to ORT, availability of ORS sachet at home, previous experience of ORT use, health-seeking behavior, and knowledge of primary caregivers were assessed. Regarding access to ORT, 173 (74.2\%) of caregivers had access to ORT when they want It. The majority, $161(69.1 \%)$ of caregivers had no ORS sachet at home. Of all, $155(66.5 \%)$ of caregivers had previous experience of ORT use any time in the past. Concerning the healthseeking behavior of caregivers, 172 (73.8\%) had sought advice or treatment from health facilities when their children had a diarrheal disease.

\section{Primary Caregivers Knowledge}

The study indicated that about $98 \%$ of the participants heard about ORT as managing under-five diarrhea. From these, 96 (41.2\%) heard from Health Extension Workers (HEWs), $94(40.3 \%)$ from the health force, and the remaining $33(14.2 \%)$ and $6(2.6 \%)$ were heard from media and friends/relatives, respectively. Among the study participants, 113 (48.5\%) had good knowledge of ORT utilization. The majority of caregivers, $146(62.7 \%)$, knew that the importance of ORT is to replace the lost fluid with diarrhea. Seventy-three (31.3\%) of participants stated that ORT is started immediately after the start of diarrhea while $97(41.6 \%)$ within the same day at any time. The remaining $33(14.2 \%)$ stated use of ORT on the second day and $7(3 \%)$ on the third day after the start of diarrhea. The rest $23(9.9 \%)$ stated they had no idea about the use of ORT after diarrheal disease onset. The majority, 141 (60.5\%), of caregivers correctly mentioned how to prepare ORT. Concerning the duration of prepared ORT use, 152 (65.5\%), 73 (31.3\%), 4 (1.7\%) of caregivers stated that it is used within $24 \mathrm{hrs}, 48 \mathrm{hrs}$, and $72 \mathrm{hrs}$, respectively. While the remaining 4 (1.7\%) answered, they had no idea about the prepared ORT duration. This study showed that $167(71.7 \%)$ of caregivers used recommended homemade fluid that includes saltsugar solution $49(21 \%)$, sugar solution $12(5.2 \%)$, rice water $150(64.4 \%)$, and soup $140(60.1 \%)$.

\section{Primary Caregivers' Perception of the Causes and Morbidity of Diarrhea}

Concerning caregivers' perception, 179 (76.8\%) answered that food/water contamination causes under-five diarrhea. The remaining 165 (70.8\%), 88 (37.8\%), and 25 (10.7\%) of 
Table I Distribution of Socio-Demographic Variables Among Mothers/Caregivers and Children with ORT Utilization in Debre Berhan Town, 2020

\begin{tabular}{|c|c|c|c|}
\hline Variables & Category & $\begin{array}{l}\text { Frequency } \\
(n=233)\end{array}$ & $\begin{array}{l}\text { Percentage } \\
\text { (\%) }\end{array}$ \\
\hline $\begin{array}{l}\text { Age of children in } \\
\text { Month }\end{array}$ & $\begin{array}{l}0-11 \\
12-23 \\
24-35 \\
36-47 \\
48-59\end{array}$ & $\begin{array}{l}50 \\
72 \\
59 \\
34 \\
18\end{array}$ & $\begin{array}{l}21.5 \\
30.9 \\
25.3 \\
14.6 \\
7.7\end{array}$ \\
\hline Sex of children & $\begin{array}{l}\text { Male } \\
\text { Female }\end{array}$ & $\begin{array}{l}132 \\
101\end{array}$ & $\begin{array}{l}56.7 \\
43.3\end{array}$ \\
\hline Age of caregiver & $\begin{array}{l}<25 y r \\
25-35 y r \\
36-45 y r \\
>45 y r\end{array}$ & $\begin{array}{l}36 \\
148 \\
40 \\
9\end{array}$ & $\begin{array}{l}15.5 \\
63.5 \\
17.2 \\
3.9\end{array}$ \\
\hline Sex of caregiver & $\begin{array}{l}\text { Female } \\
\text { Male }\end{array}$ & $\begin{array}{l}213 \\
20\end{array}$ & $\begin{array}{l}91.4 \\
8.6\end{array}$ \\
\hline $\begin{array}{l}\text { Marital status of } \\
\text { the caregiver }\end{array}$ & $\begin{array}{l}\text { Single } \\
\text { Married } \\
\text { Divorce } \\
\text { Widowed }\end{array}$ & $\begin{array}{l}14 \\
203 \\
10 \\
6\end{array}$ & $\begin{array}{l}6.0 \\
87.1 \\
4.3 \\
2.6\end{array}$ \\
\hline Ethnicity & $\begin{array}{l}\text { Amhara } \\
\text { Oromo } \\
\text { Gurage } \\
\text { Tigre }\end{array}$ & $\begin{array}{l}167 \\
28 \\
32 \\
6\end{array}$ & $\begin{array}{l}71.7 \\
12.0 \\
13.7 \\
2.6\end{array}$ \\
\hline Religion & $\begin{array}{l}\text { Orthodox } \\
\text { Muslim } \\
\text { Protestant } \\
\text { Catholic }\end{array}$ & $\begin{array}{l}142 \\
35 \\
43 \\
13\end{array}$ & $\begin{array}{l}60.9 \\
15.0 \\
18.5 \\
5.6\end{array}$ \\
\hline $\begin{array}{l}\text { Occupational } \\
\text { status of the } \\
\text { caregiver }\end{array}$ & $\begin{array}{l}\text { House-wife } \\
\text { Private } \\
\text { Employed } \\
\text { Others } \\
\text { (student + } \\
\text { laborer) }\end{array}$ & $\begin{array}{l}111 \\
61 \\
54 \\
7\end{array}$ & $\begin{array}{l}47.6 \\
26.2 \\
23.2 \\
3.0\end{array}$ \\
\hline $\begin{array}{l}\text { Monthly income in } \\
\text { ETB }\end{array}$ & $\begin{array}{l}<500 \text { birr } \\
50 \mathrm{I}-1000 \\
100 \mathrm{I}-3000 \\
>3000\end{array}$ & $\begin{array}{l}9 \\
10 \\
39 \\
175\end{array}$ & $\begin{array}{l}3.9 \\
4.3 \\
16.7 \\
75.1\end{array}$ \\
\hline Family size & $\begin{array}{l}\text { Less than or } \\
\text { equal to } 5 \\
\text { Above } 5\end{array}$ & $\begin{array}{l}201 \\
32\end{array}$ & $\begin{array}{l}86.3 \\
13.7\end{array}$ \\
\hline $\begin{array}{l}\text { Under-five children } \\
\text { number }\end{array}$ & $\begin{array}{l}1 \\
\geq 2\end{array}$ & $\begin{array}{l}170 \\
63\end{array}$ & $\begin{array}{l}73 \\
27\end{array}$ \\
\hline
\end{tabular}

(Continued)
Table I (Continued).

\begin{tabular}{|l|l|l|l|}
\hline Variables & Category & $\begin{array}{l}\text { Frequency } \\
\text { (n=233) }\end{array}$ & $\begin{array}{l}\text { Percentage } \\
\text { (\%) }\end{array}$ \\
\hline Relation of & Mother & 185 & 79.4 \\
caregiver to child & Father & 22 & 9.4 \\
& Sister & 8 & 3.4 \\
& Brother & 2 & 0.9 \\
& Grandmother & 16 & 6.9 \\
\hline
\end{tabular}

caregivers replied that tooth eruption, weaning, and evil-eye causes under-five diarrhea, respectively. Regarding morbidity of diarrhea, most caregivers, and 220 (94.4\%), identified two or more severity signs of diarrhea. While $186(79.8 \%)$ primary givers recognized two or more severity signs of diarrhea. The remaining caregivers recognized at least one severe sign of diarrhea and dehydration.

\section{Factors Associated with Oral}

\section{Rehydration Therapy Among Caregivers of Under-Five Children}

Those variables which have a $p$-value $\leq 0.25$ during bivariate logistic regression analysis were to multivariable logistic regression analysis. The variables include the age of caregivers, educational status of caregivers, access to ORT, availability of ORS sachet at home, previous use of ORT, health-seeking behavior, knowledge about ORT, caregivers' perception about the causes and morbidity of diarrhea-like contamination, tooth eruption, evil eye, weaning, and several identified signs to recognize the severity of dehydration. After multivariable logistic analysis at $95 \%$ confidence interval, previous use of ORT, health-seeking behavior, knowledge about ORT, caregivers' perception of tooth eruption and weaning as causes of diarrhea, and several identified signs to recognize the severity of dehydration remained significantly associated with ORT utilization.

Primary caregivers who had previous experience of using ORT were nearly five times higher in odds to give ORT to manage under-five diarrhea than those who had no prior knowledge of using ORT [AOR=5.31, 95\% CI: 2.11, 13.32]. Likewise, primary caregivers who had good health-seeking behavior had five and a half higher odds to use ORT to manage under-five diarrhea compared to 
their counterparts [AOR $=5.68,95 \%$ CI: 2.07, 15.62]. Primary caregivers who perceived that weaning and tooth eruption as causes of diarrhea had about seven and three times higher odds to give ORT for their children for the management of under-five diarrhea compared to those who do not perceive $[\mathrm{AOR}=6.68,95 \% \mathrm{CI}: 2.50,17.85$, and [AOR $=3.13,95 \%$ CI: $1.08,9.04]$, respectively. Primary caregivers who had good knowledge about ORT had four times higher odds to use ORT for the management of under-five diarrhea compared to those who had poor knowledge $[\mathrm{AOR}=4.22,95 \% \mathrm{Cl}: 1.70,10.46]$. Finally, primary caregivers who could identify two or more signs to recognize the severity of dehydration were about sixfolds higher to use ORT to manage under-five diarrhea than their counterparts $[\mathrm{AOR}=5.64,95 \% \mathrm{Cl}: 2.16,14.74]$ [Table 2].

\section{Discussion}

In this study, the prevalence of ORT use was 73\% [95\% $\mathrm{Cl}: 66.8$ 78.6]. The result is higher than previous studies done in Ethiopia Asela town 58.2\%), ${ }^{7}$ Ethiopia Dangure district (51\%), ${ }^{15}$ Kenya (61\%), ${ }^{19}$ Cameroon $(65.9 \%),{ }^{18}$ and Nigeria $(61.8 \%) .^{20}$ This difference might be due to socio-demographic variations among caregivers in an urban area. The current study done in an urban area near to the capital city of Ethiopia, and the people are better educated. They have more access to health information about ORT use and its importance. Another reason might be because our study incorporates ORS plus recommended homemade fluids.

This study revealed that primary caregivers' previous experience was positively associated with ORT use. Caregivers who had prior experience of using ORT had five times higher odds of using ORT to manage under-five diarrhea compared to those caregivers who had no prior knowledge of using ORT. This finding is consistent with a community-based cross-sectional study done in Dangure district, Ethiopia, ${ }^{15}$ and a community-based case-control study done in Kersa district, Eastern Ethiopia. ${ }^{14}$ The association might be due to the familiarity of caregivers about oral rehydration therapy.

According to this study, primary caregivers who had good health-seeking behavior had five and a half folds higher odds to use ORT for the management of under-five diarrhea compared to their counterparts. The association is in line with the study done in Dangure district, Ethiopia (19), and Kersa district, Eastern Ethiopia. ${ }^{14}$ The association might be due to the caregivers who sought care at the health facility got advice or information from health professionals that create awareness about the importance of ORT use.

Our study also showed that primary caregivers who had perceived tooth eruption and weaning as a cause of diarrhea had three and seven times higher odds of using ORT at the time of diarrheal episode. The study is in line with the study done in Kersa district, Eastern Ethiopia. ${ }^{14}$ This may be because misconception about the cause of diarrhea has negative implications on the use of ORT.

Knowledge of primary caregivers is also another significant factor for the use of ORT. Primary caregivers who had good knowledge about ORT had four times higher odds of using ORT to manage under-five diarrhea compared to those who had poor knowledge. This finding agrees with the study done in Asela tow, Ethiopia (7), Dangure district, Ethiopia (19), Kersa district, Eastern Ethiopia. ${ }^{14}$ The association might be due to those caregivers with good knowledge might have better healthcare behaviors than those who had poor knowledge.

Recognizing two or more severity signs of dehydration is another positive factor for the use of ORT. Primary caregivers who could identify two or more symptoms of the severity of dehydration were about six-folds higher to use ORT to manage under-five diarrhea than their counterparts. According to our study, $86.7 \%$ of caregivers who identified two or more severity signs of dehydration had good knowledge about ORT and $80.8 \%$ of sought healthcare. The knowledge of the caregivers may allow the primary caregivers to give ORT during diarrheal disease.

\section{Limitation of the Study}

Data collection was based on the self-report of primary caregivers. Recall bias might underestimate the prevalence of oral rehydration therapy. Social desirability might also be another problem in some advice and healthcare-seeking responses from health facilities.

\section{Conclusion}

Nearly two-thirds of the mothers give oral rehydration therapy while their child develops diarrhea. Mothers had previous oral rehydration therapy, good health-seeking behavior, knowledge about oral rehydration therapy, caregivers' perception of tooth eruption, and weaning as causes of diarrhea. Signs to recognize the severity of dehydration were important factors with oral rehydration therapy utilization. It will be better to give mothers special attention to hindering factors from giving oral rehydration therapy for their beloved child during diarrheal disease. 
Table 2 Bivariate and Multivariate Analysis to Identify Associated Factors of ORT Utilization Among Primary Caregivers in Debre Berhan Town, 2020

\begin{tabular}{|c|c|c|c|c|c|c|}
\hline \multirow[t]{2}{*}{ Variables } & \multirow[t]{2}{*}{ Category } & \multicolumn{2}{|c|}{ ORT Use } & \multirow[t]{2}{*}{ COR $(95 \% \mathrm{CL})$} & \multirow[t]{2}{*}{ AOR (95\% CL) } & \multirow{2}{*}{$\begin{array}{l}\text { P-value } \\
\text { (AOR) }\end{array}$} \\
\hline & & No & Yes & & & \\
\hline \multirow[t]{5}{*}{ Age of caregivers } & $<25 y r$ & 8 & 28 & $7.0(1.42,34.43)$ & $1.85(0.20,17.28)$ & 0.49 \\
\hline & $25-35 y r$ & 36 & 112 & $6.22(1.48,26.15)$ & $1.33(0.17,10.54)$ & 0.28 \\
\hline & $36-45 y r$ & 13 & 27 & 4.154(0.89, & $1.47(0.17,12.62)$ & 0.26 \\
\hline & & & & 19.29) & & \\
\hline & $>45 y r$ & 6 & 3 & 1 & I & - \\
\hline \multirow[t]{4}{*}{ Caregivers educational level } & No education & 11 & 13 & I & 1 & - \\
\hline & Primary & 27 & 66 & $2.07(0.83,5.19)$ & $0.56(0.12,2.88)$ & 0.59 \\
\hline & Secondary & 14 & 54 & $3.26(1.21,8.83)$ & $0.39(0.07,2.20)$ & 0.79 \\
\hline & College and above & 11 & 37 & $2.85(0.10,8.12)$ & $0.35(0.05,2.22)$ & 0.73 \\
\hline \multirow[t]{2}{*}{ Access to ORT } & No & 27 & 33 & I & I & - \\
\hline & Yes & 36 & 137 & $3.1 \mathrm{I}(1.66,5.83)$ & $1.35(0.45,4.02)$ & 0.59 \\
\hline \multirow[t]{2}{*}{ ORS sachet availability } & No & 52 & 109 & I & 1 & - \\
\hline & Yes & 11 & 61 & $2.65(1.29,5.45)$ & $1.19(0.42,3.35)$ & 0.75 \\
\hline \multirow[t]{2}{*}{ Experience for ORT use } & No & 40 & 38 & I & 1 & - \\
\hline & Yes & 23 & 132 & $6.04(3.23,11.31)$ & 5.31 (2.11, 13.32) & 0.00 \\
\hline \multirow[t]{2}{*}{ Healthcare seeking } & No & 34 & 27 & 1 & I & - \\
\hline & Yes & 29 & 143 & $6.2 \mathrm{I}(3.26,1 \mathrm{I} .82)$ & $5.68(2.07,15.62)$ & 0.001 \\
\hline \multirow{2}{*}{$\begin{array}{l}\text { Contamination of food/ } \\
\text { water }\end{array}$} & No & 19 & 35 & 1 & I & - \\
\hline & Yes & 44 & 135 & $\mathrm{I} .67(0.87,3.20)$ & $0.64(0.22,1.88)$ & 0.42 \\
\hline \multirow[t]{2}{*}{ Tooth eruption } & Yes & 12 & 56 & $2.09(1.03,4.23)$ & $3.13(1.08,9.04)$ & 0.04 \\
\hline & No & 51 & 114 & 1 & I & - \\
\hline \multirow[t]{2}{*}{ Weaning } & Yes & 22 & 123 & $4.88(2.63,9.04)$ & $(6.68(2.50,17.85)$ & 0.001 \\
\hline & No & $4 I$ & 47 & 1 & i & - \\
\hline \multirow[t]{2}{*}{ Knowledge about ORT } & Poor & 53 & 67 & I & I & - \\
\hline & Good & 10 & 103 & $8.15(3.88,17.12)$ & $4.22(1.70,10.46)$ & 0.002 \\
\hline \multirow[t]{2}{*}{ Dehydration Severity signs } & I & 26 & 21 & I & I & - \\
\hline & $\geq 2$ & 37 & 149 & $4.99(2.53,9.83)$ & $5.64(2.16,14.74)$ & 0.001 \\
\hline
\end{tabular}

\section{Abbreviation}

ORS, oral rehydration therapy.

\section{Data Sharing Statement}

The datasets used, and analyzed during the current study are available from the corresponding author on reasonable request.

\section{Ethics Approval}

Helsinki declaration for medical research involving human subjects was followed. Ethical clearance was obtained from the Institutional Health Research Review Committee (Ref. No/ NURS/16/2021) of the college of health and medicine, Debre Berhan University. Ethical clearance was obtained from the
Institutional Health Research Review Committee of Debre Berhan University, college of health science. A permission letter was written for each study health institution, and a permission letter was taken from the study institution administrator. Written informed consent was taken from each study participant.

\section{Consent for Publication}

The manuscript did not contain individuals' detailed data in any form.

\section{Author Contributions}

All authors made substantial contributions to conception and design, acquisition of data, or analysis and interpretation of 
data; took part in drafting the article or revising it critically for important intellectual content; agreed to submit to the current journal; gave final approval of the version to be published; and agreed to be accountable for all aspects of the work.

\section{Funding}

The study authors covered the budget needed for this research.

\section{Disclosure}

The authors declare that they have no conflicts of interest for this work.

\section{References}

1. World Health Organization. Diarrhoea: Why Children are Still Dying and What Can Be Done; 2009.

2. Wold Health Organization. The Treatment of Diarrhoea: A Manual for Physicians and Other Senior Health Workers. World Health Organization; 2005.

3. Suh J-S, Hahn W-H, Cho B-S. Recent advances of oral rehydration therapy (ORT). Electrolyte Blood Press. 2010;8(2):82-86. doi:10.5049/EBP.2010.8.2.82

4. Sreeramareddy CT, Low Y-P, Forsberg BC. Slow progress in diarrhea case management in low and middle income countries: evidence from cross-sectional national surveys, 1985-2012. BMC Pediatr. 2017;17 (1):1-8. doi:10.1186/s12887-017-0836-6

5. Kadam D, Hadaye R, Pandit D. Knowledge and practices regarding oral rehydration therapy among mothers in rural area of Vasind, India. Nepal Med Coll J. 2012;15(2):110-112.

6. Mohammed S, Tamiru D. The burden of diarrheal diseases among children under five years of age in Arba Minch District, Southern Ethiopia, and associated risk factors: a cross-sectional study. Int Sch Res Notices. 2014;2014:1-6. doi:10.1155/2014/654901

7. Adanech E. Assessment of Knowledge, Practice and Utilization of Oral Rehydration Therapy for Acute Watery Diarrhoeal Disease Case Management Among Mothers (Caregivers') of Under-Five Children in Assela Town, Ethiopia. Addis Ababa University; 2015.

8. Binder HJ, Brown I, Ramakrishna B, Young GP. Oral rehydration therapy in the second decade of the twenty-first century. Curr Gastroenterol Rep. 2014;16(3):376. doi:10.1007/s11894-014-0376-2

9. Roser M, Ritchie H, Dadonaite B. Child and infant mortality. Our World in Data. 2013.
10. Gazi E, Chowdhury A, Kumar R, Sarkar AP, Basu S, Saha S. Can mothers care for acute diarrhoeal disease of their under five children effectively at home? A cross sectional study in slum community in bankura. J Evid Based Medi Healthc. 2015;2(36):5575-5584. doi:10.18410/jebmh/2015/772

11. Lenters LM, Das JK, Bhutta ZA. Systematic review of strategies to increase use of oral rehydration solution at the household level. $B M C$ Public Health. 2013;13(3):1-8. doi:10.1186/1471-2458-13-S3-S28

12. Alebel A, Tesema C, Temesgen B, Gebrie A, Petrucka P, Kibret GD. Prevalence and determinants of diarrhea among under-five children in Ethiopia: a systematic review and meta-analysis. PLoS One. 2018;13 (6):e0199684. doi:10.1371/journal.pone.0199684

13. Central Demographic Agency of Ethiopia. Health Survey-2011. Central Statistical Agency Addis Ababa. Vol. 2016. Maryland, USA: Ethiopia ICF International Calverton; 2012.

14. Mengistie B, Berhane Y, Worku A. Predictors of oral rehydration therapy use among under-five children with diarrhea in Eastern Ethiopia: a community based case control study. BMC Public Health. 2012;12(1):1-7. doi:10.1186/1471-2458-12-1029

15. Misgna HG, Ebessa B, Kassa M. Prevalence of oral rehydration therapy use and associated factors among under-five children with diarrhea in Dangure, Benishangul Gumuz Region, Ethiopia/2018. BMC Res Notes. 2019;12(1):1-6. doi:10.1186/s13104-019-4078-6

16. Jose DL, Purushothaman P, Lakshmanan RSS. How knowledgeable and practicable are the mothers of under five children in urban slum, Tamil Nadu on: utilization of ORS, homemade fluids and feeding practices during acute diarrhoeal diseases. Int J Community Med Public Health. 2019;6(8):3502. doi:10.18203/2394-6040. ijcmph20193479

17. Okafor CE, Ekwunife OI, Rabaa MA. Cost-effectiveness analysis of diarrhoea management approaches in Nigeria: a decision analytical model. PLoS Negl Trop Dis. 2017;11(12):e0006124. doi:10.1371/ journal.pntd.0006124

18. Essomba NE, Koum DK, Adiogo D, Ngwe M, Coppieters Y. Use of oral rehydration therapy in the treatment of childhood diarrhoea in Douala, Cameroon. Malawi Med J. 2015;27(2):60-64. doi:10.4314/ mmj.v27i2.6

19. Olson CK, Blum LS, Patel KN, et al. Community case management of childhood diarrhea in a setting with declining use of oral rehydration therapy: findings from cross-sectional studies among primary household caregivers, Kenya, 2007. Am J Trop Med Hyg. 2011;85 (6):1134-1140. doi:10.4269/ajtmh.2011.11-0178

20. Agbolade M, Dipeolu I, Ajuwon A. Knowledge and use of oral rehydration therapy among mothers of under-five children in a Military Barrack in Ibadan, Nigeria. Afr J Biomed Res. 2015;18 (1):7-15.
Pediatric Health, Medicine and Therapeutics

\section{Publish your work in this journal}

Pediatric Health, Medicine and Therapeutics is an international, peerreviewed, open access journal publishing original research, reports, editorials, reviews and commentaries. All aspects of health maintenance, preventative measures and disease treatment interventions are addressed within the journal. Practitioners from all disciplines are invited to submit their work as well as healthcare researchers and patient support groups. The manuscript management system is completely online and includes a very quick and fair peer-review system. Visit http://www.dovepress.com/testimonials.php to read real quotes from published authors. 